\title{
Supporting Information For A Colorimetric and Fluorometric Dual-Model Assay for Mercury lon by a molecule
}

\author{
Mingjian Yuan, ${ }^{\dagger}$ Yuliang $\mathrm{Li}^{\dagger}{ }^{\dagger}, *$ Junbo $\mathrm{Li},{ }^{\dagger}$ Cuihong \\ $\mathrm{Li}^{\dagger}{ }^{\dagger}$ Xiaofeng Liu, ${ }^{\dagger}$ Jing Lv, ${ }^{\dagger}$ Jialiang $\mathrm{Xu},{ }^{\dagger}$ Huibiao \\ Liu, ${ }^{\dagger}$ Shu Wang, ${ }^{\dagger}$ Daoben $\mathrm{Zhu}^{\dagger}$ \\ Beijing National Laboratory for Molecular Sciences \\ (BNLMS),CAS Key Laboratory of Organic Solids, Institute of \\ Chemistry, Chinese Academy of Sciences $\square$ and Graduate school of \\ the Chinese Academy of Sciences, Beijing 100080, P.R. China
}

Table of contents:

§1. Materials.

\section{§2.Measurements.}

§3.Methods.

§4.Photophysical Properties of Compounds DMS1, 3, 4,

§5.Binding Analysis for each of the two receptors.

1). Binding Analysis for the meso-position receptor.

2). Binding Analysis for the styryl-extended receptor.

§6. Synthesis.

§7. The characterization data of all compounds. 


\section{§1. Materials.}

Unless otherwise stated, reagents were commercially obtained and use without further purification. 10-Phenyl-1,4-dioxa- 7,13-dithia-10-azacyclopentadecane (1) ${ }^{11}$ and 4,4-Difluoro-1,3,5,7-tetramethyl-8-phenyl-4-bora-3a,4a,-diaza-s-indcene $\quad(5)^{8 \mathrm{a}}$ were synthesized according to the literature.

\section{§2. Measurements.}

The absorption spectra were measured on a Hitachi U-3010 spectrometer. Fluorescence spectra were measured on a Hitachi F-4500 fluorometer. ${ }^{1} \mathrm{H}$ NMR and ${ }^{13} \mathrm{C}$ NMR spectra were obtained on a Bruker Avance DPS-400 spectrometer, respectively. MALDI-TOF mass spectrometric measurements were performed on Bruker Biflex III MALDI-TOF (both positive and negative ion reflector mode). Elemental analyses were carried out on a Carlo Erba 1106 elemental analyzer.

\section{§3. Methods.}

The quantum yield of DMS1, 3, 4 were determined with fluorescein in $1 \mathrm{~N} \mathrm{NaOH}(\phi=$ $0.95)$ as a reference. ${ }^{12}$ All the quantum yield were determined in the solutions of THF-water (30:70, v/v, 20mM HEPES buffer, $\mathrm{pH}$ 7.2) at room temperature. Excitation was at 540nm for DMS1 and the $\mathrm{Hg}(\square)$ complex.

Benesi-Hildebrand plots:

$$
\begin{aligned}
& 1 \square \mathrm{I}_{0} \square \mathrm{I} \square 1 \square \mathrm{K}\left(\mathrm{I}_{0} \square \mathrm{I}\right) \times 1 \square[\mathrm{M}] \square 1 \square \mathrm{I}_{0} \square \mathrm{I} \\
& \mathrm{K}=\text { Binding constant; } \\
& \mathrm{I}_{0}=\text { The observed Fluorescence intensity in the absence of cation ; } \\
& \mathrm{I}=\text { The observed Fluorescence intensity of the cation-added ; }
\end{aligned}
$$




\section{§4.Photophysical Properties of Compounds DMS1, 3, 4}

Table S1. Quantum yield, Absorption and Emission Properties of all compounds:

\begin{tabular}{|c|c|l|l|}
\hline & $\Phi$ & $\lambda_{\mathrm{ab}}$ & $\lambda_{\mathrm{em}}$ \\
\hline DMS1 & 0.04 & $606 \mathrm{~nm}$ & $668 \mathrm{~nm}$ \\
\hline DMS1+Hg & 0.33 & $564 \mathrm{~nm}$ & $578 \mathrm{~nm}$ \\
\hline 3 & 0.02 & $498 \mathrm{~nm}$ & $519 \mathrm{~nm}$ \\
\hline $3+\mathrm{Hg}^{2+}$ & 0.42 & $499 \mathrm{~nm}$ & $520 \mathrm{~nm}$ \\
\hline 4 & 0.10 & $601 \mathrm{~nm}$ & $670 \mathrm{~nm}$ \\
\hline $4+\mathrm{Hg}^{2+}$ & 0.36 & $566 \mathrm{~nm}$ & $577 \mathrm{~nm}$ \\
\hline
\end{tabular}

\section{§5. Binding Analysis for each of the two receptors.}

1) Binding Analysis for the meso-position receptor

a) job's plot
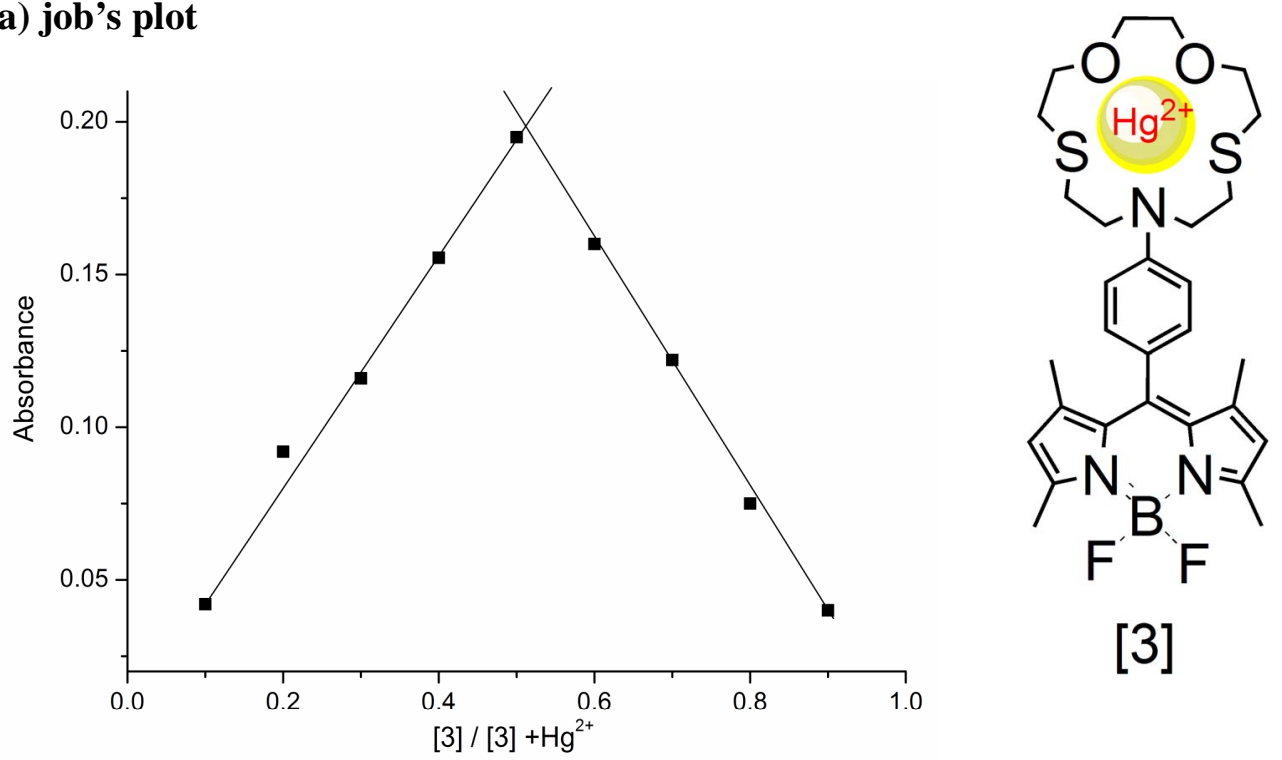

Figure S1. Job's plot of 1:1 complexes of meso-receptor and $\mathrm{Hg}^{2+}$, where the absorption at 520nm was plotted against the mole fraction of compound 3 . 


\section{b) Benesi-Hildebrand plots}

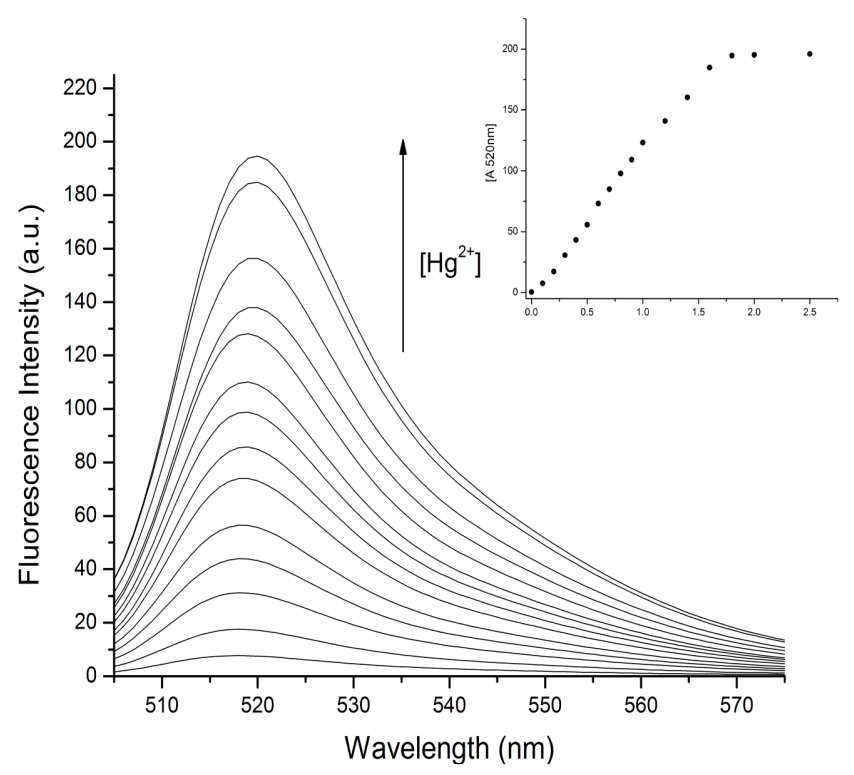

Figure S2. Emission spectra of compound $3\left(2 \times 10^{-5} \mathrm{M}\right)$ in the presence of increasing $\mathrm{Hg}$ (II) in a THF-water solution (30:70, v/v, 20mM HEPES buffer, $\mathrm{pH} 7.2$ ) at $25{ }^{\circ} \mathrm{C}$. Inset: Variation of Fluorescence intensity at $520 \mathrm{~nm}$ of compound 3 with increasing $\mathrm{Hg}^{2+}$ concentrations.

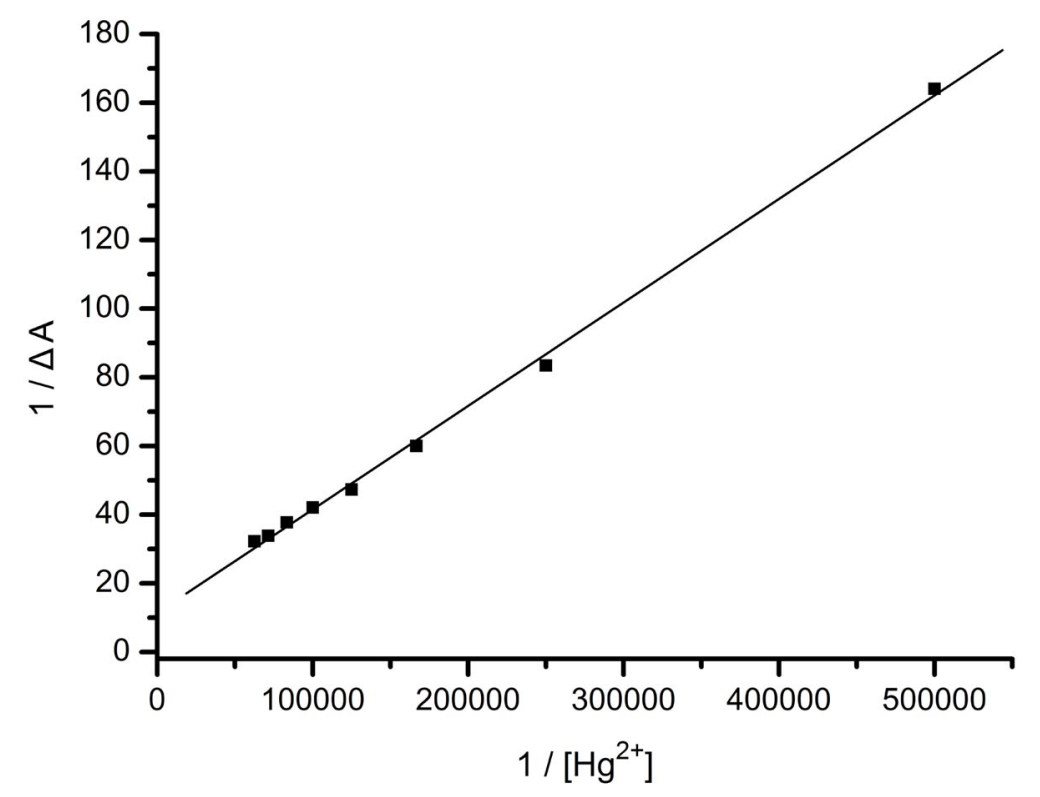

Figure S3. Benesi-Hildebrand analysis of compound 3 (meso-receptor) at different $\mathrm{Hg}^{2+}$ concentrations. 
Equation: $\mathrm{Y}=\mathrm{A}+\mathrm{BX}$

\begin{tabular}{|c|c|c|c|}
\hline Parameter & Value & \multicolumn{2}{|c|}{ Error } \\
\hline A & 12.61423 & \multicolumn{2}{|c|}{0.19951} \\
\hline $\mathrm{B}$ & $3.0144 \times 10^{-4}$ & \multicolumn{2}{|c|}{$5.49038 \times 10^{-6}$} \\
\hline $\mathrm{R}$ & SD & $\mathrm{N}$ & $\mathrm{P}$ \\
\hline 0.99901 & 2.13367 & 8 & $<0.0001$ \\
\hline \multicolumn{4}{|c|}{$\begin{array}{l}\mathrm{Ks}=\mathrm{A} / \mathrm{B}=(12.61423 / 3.0144) \times 10^{4}=4.185 \times 10^{4} \\
\Delta \mathrm{Ks}=\mathrm{I} \Delta \mathrm{A} / \mathrm{A}-\Delta \mathrm{B} / \mathrm{B} \text { । } \times \mathrm{Ks}=0.013 \times 10^{4} \\
\mathrm{~K}=\mathrm{Ks}+\Delta \mathrm{Ks}=(4.185 \pm 0.013) \times 10^{4}\end{array}$} \\
\hline
\end{tabular}

\section{2) Binding Analysis for the styryl-extended receptor}
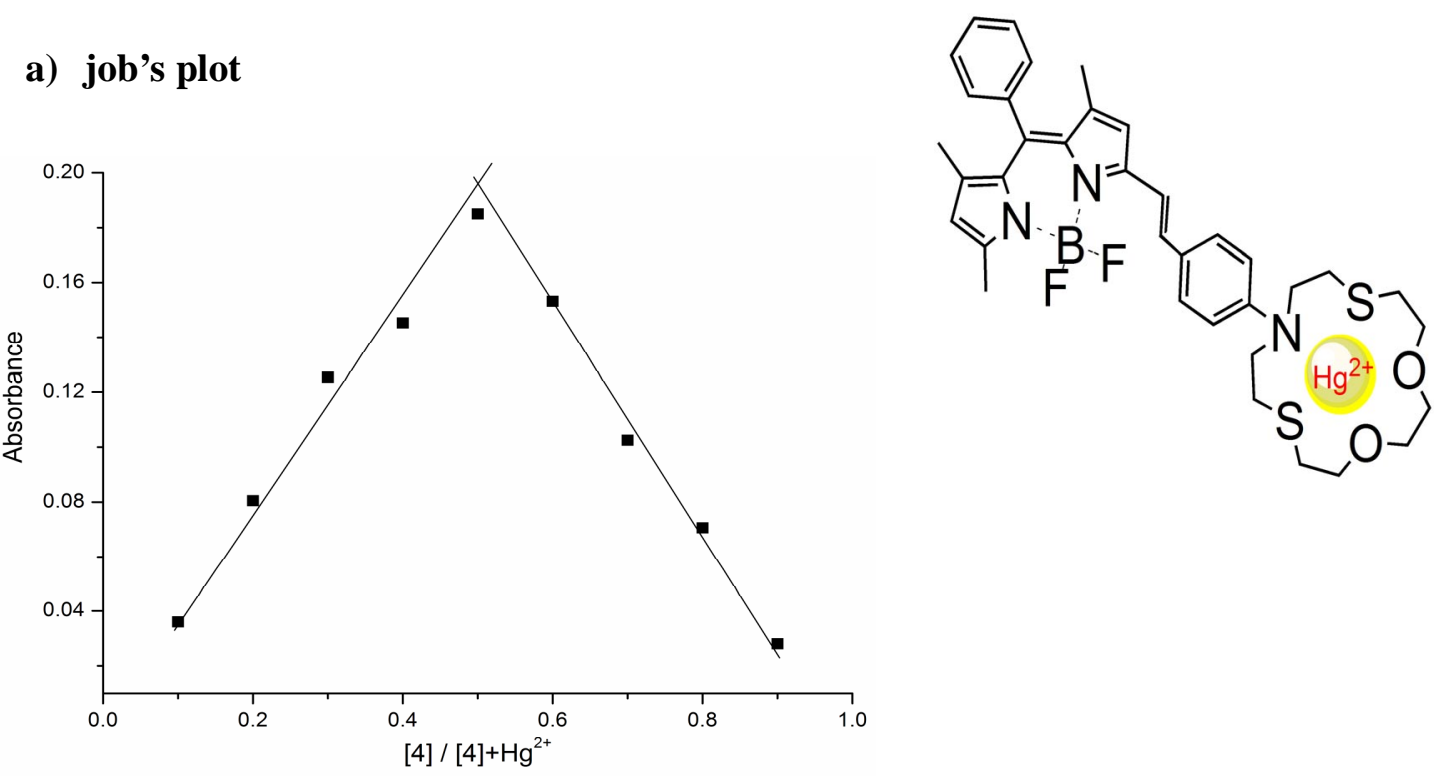

Figure S4. Job's plot of 1:1 complexes of styryl-extended receptor (compound 4) and $\mathrm{Hg}^{2+}$, where the absorption at 566nm was plotted against the mole fraction of compound 4. 


\section{b) Benesi-Hildebrand plots}

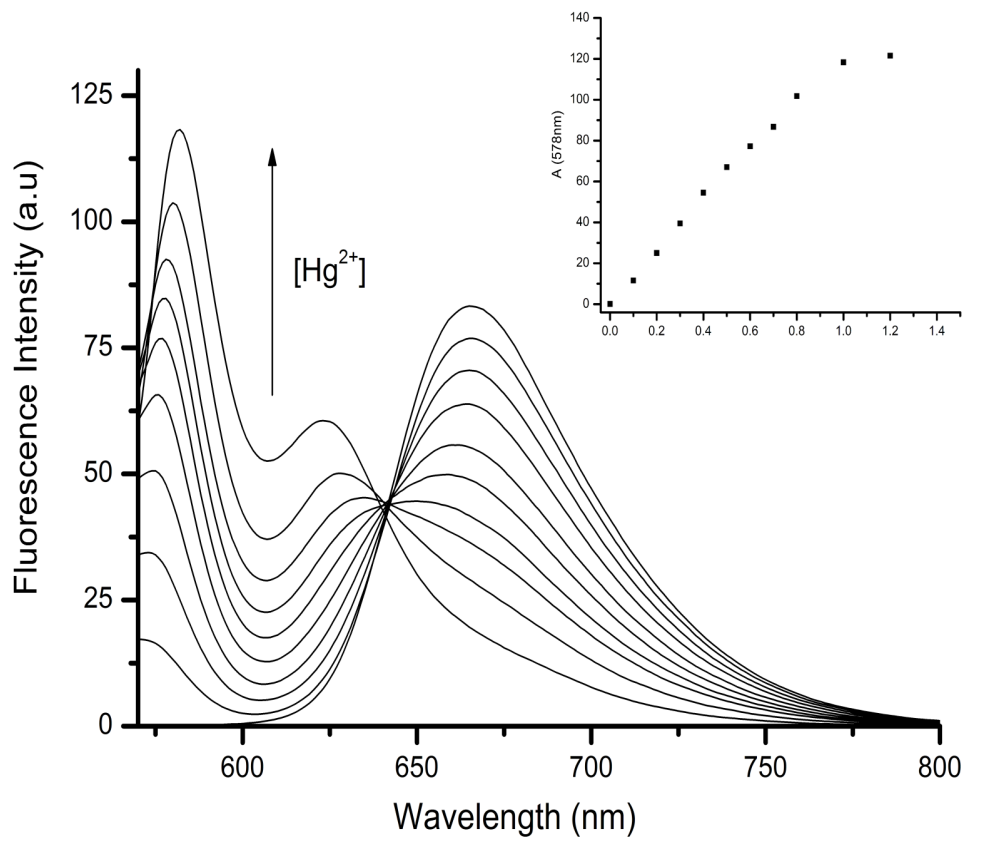

Figure S5. Emission spectra of compound $4\left(2 \times 10^{-5} \mathrm{M}\right)$ in the presence of increasing $\mathrm{Hg}$ (II) in a THF-water solution (30:70, v/v, 20mM HEPES buffer, $\mathrm{pH} 7.2$ ) at $25{ }^{\circ} \mathrm{C}$. Inset: Variation of Fluorescence intensity at $578 \mathrm{~nm}$ of compound 3 with increasing $\mathrm{Hg}^{2+}$ concentrations.

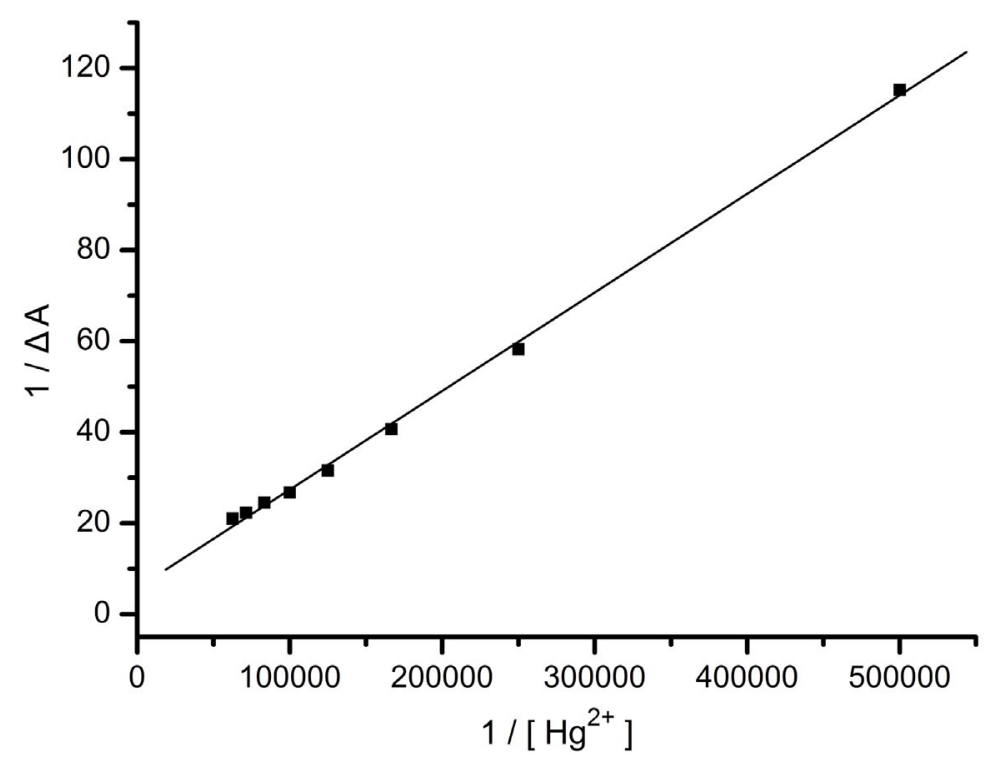

Figure S6. Benesi-Hildebrand analysis of compound 4 (styryl-extended receptor) at different $\mathrm{Hg}^{2+}$ concentrations. 


\begin{tabular}{lccc} 
Equation: $\mathrm{Y}=\mathrm{A}+\mathrm{BX}$ & & \\
Parameter & Value & Error \\
$\mathrm{A}$ & 6.26721 & & 0.4061 \\
$\mathrm{~B}$ & $2.16632 \times 10^{-4}$ & & $3.69003 \times 10^{-6}$ \\
$\mathrm{R}$ & $\mathrm{SD}$ & $\mathrm{N}$ & $\mathrm{P}$ \\
0.99913 & 1.43405 & 8 & $<0.0001$ \\
\multicolumn{5}{c}{} \\
$\mathrm{Ks}=\mathrm{A} / \mathrm{B}=(6.26721 / 2.16632) \times 10^{4}=2.893 \times 10^{4}$ \\
$\Delta \mathrm{Ks}=\mathrm{I} \Delta \mathrm{A} / \mathrm{A}-\Delta \mathrm{B} / \mathrm{B}$ । $\times \mathrm{Ks}=0.13 \times 10^{4}$ \\
$\mathrm{~K}=\mathrm{Ks}+\Delta \mathrm{Ks}=(2.893 \pm 0.13) \times 10^{4}$
\end{tabular}

\section{§6. Synthesis:}

\section{1,4-Dioxa-7,13-dithia-10-(4-formylphenyl)-10-azacyclopentadecane(2):}

10-Phenyl-1,4-dioxa-7,13-dithia-10-azacyclopentadecane $\quad(220 \mathrm{mg}, \quad 0.7 \mathrm{mmol})$ was dissolved in dry DMF $(10 \mathrm{~mL})$ in a $25 \mathrm{ml}$ flask and cooled in an ice bath. To the solution was dropwise added $\mathrm{POCl}_{3}(215.1 \mathrm{mg}, 1.41 \mathrm{mmol})$ for $5 \mathrm{~min}$. After the addition was complete the solution was stirred in ac ice bath for another 10min, at room temperature for $12 \mathrm{~h}$. and then, heated at $90 \square$ for $1.5 \mathrm{~h}$. After the reaction was completed, the mixture was poured into the ice water $(20 \mathrm{~mL})$ and neutralized with sodium acetate then extracted with $\mathrm{CHCl}_{3}$. The combined organic phases were dried over $\mathrm{Na}_{2} \mathrm{SO}_{4}$, and the solvent was removed under vacuum. The crude residue was purified by silica gel chromatograph with $\mathrm{CH}_{2} \mathrm{Cl}_{2}$ as eluant, yielding a white solid $(157.5 \mathrm{mg}, 63 \%){ }^{1} \mathrm{H}$ NMR (400MZ, $\left.\mathrm{CDCl}_{3}\right): \delta 9.69(\mathrm{~S}, 1 \mathrm{H}), 7.69$ (d, 2H, J=8.66Hz), $6.64(\mathrm{~d}, 2 \mathrm{H}, J=8.66 \mathrm{~Hz})$ $3.79\left(\mathrm{t}, 4 \mathrm{H}, J=7 \mathrm{~Hz}, \mathrm{~N}-\mathrm{CH}_{2}-\mathrm{CH}_{2}-\mathrm{S}\right), 3.65\left(\mathrm{t}, 4 \mathrm{H}, J=7 \mathrm{~Hz}, \mathrm{O}-\mathrm{CH}_{2}-\mathrm{CH}_{2}-\mathrm{S}\right), 3.61(\mathrm{~S}, 4 \mathrm{H}$, $\mathrm{O}-\mathrm{CH}_{2}-\mathrm{CH}_{2}-\mathrm{O}$ ), 2.88 (t, 4H,J=7Hz,N-CH$\left.-\mathrm{CH}_{2}-\mathrm{S}\right), 2.73$ (t, 4H, J=7Hz, O-CH $\mathrm{CH}_{2}-\mathrm{CH}_{2}-\mathrm{S}$ ) 
${ }^{13} \mathrm{C}$ NMR (100MZ, $\left.\mathrm{CDCl}_{3}\right):$ б29.3, 31.4, 52.0, 70.7, 74.3, 111.1, 125.4, 132.3, 151.7, 190.0 .

\section{4,4-Difluoro-8-[1,4-dioxa-7,13-dithia-10-(4-formyphenyl)-10-azacyclopentadecan yl]-1,3,5,7-tetramethyl-4-bora-3a,4a-diaza-s-indacene(3)}

1,4-Dioxa-7,13-dithia-10-(4-formylphenyl)-10-azacyclopentadecane （165mg, 0.48mmol) and 2,4-dimethylpyrrole $(92.1 \mathrm{mg}, 0.97 \mathrm{mmol})$ were dissolved in anhydrous $\mathrm{CH}_{2} \mathrm{Cl}_{2}$ (100mL) under $\mathrm{N}_{2}$ atmosphere. One drop of trifluoroacetic acid was added, and the light red solution was stirred at room temperature for 5h. A solution of 2,3-dichloro-5,6-dicyano-1,4-benzoquinone (109.9mg. 0.48mmol) in anhydrous $\mathrm{CH}_{2} \mathrm{Cl}_{2}(25 \mathrm{~mL})$ was added by syringe, and the resulting mixture was stirred for $15 \mathrm{~min}$ followed by the addition of $4 \mathrm{~mL}$ triethylamine and $4 \mathrm{~mL} \mathrm{BF}_{3} \cdot \mathrm{Et}_{2} \mathrm{O}$. After stirring for another $30 \mathrm{~min}$ the reaction mixture was washed with water $(4 \times 50 \mathrm{ml})$, and the organic phase was dried over $\mathrm{Na}_{2} \mathrm{SO}_{4}$. After concentration in vacuum, the residue was purified by column chromatography (silica gel, $\mathrm{CH}_{2} \mathrm{Cl}_{2}$ to $\mathrm{CH}_{2} \mathrm{Cl}_{2} / \mathrm{MeOH}=200: 1$ ) twice to afford an orange-red solid (80.65mg, 31\%) ${ }^{1} \mathrm{H}$ NMR (400MZ, $\left.\mathrm{CDCl}_{3}\right): \delta 7.04$ (d, 2H, $J=8.35 \mathrm{~Hz}), 6.70(\mathrm{~d}, 2 \mathrm{H}, J=8.35 \mathrm{~Hz}), 5.96(\mathrm{~S}, 2 \mathrm{H}), 3.82\left(\mathrm{t}, 4 \mathrm{H}, J=5 \mathrm{~Hz}, \mathrm{~N}-\mathrm{CH}_{2}-\mathrm{CH}_{2}-\mathrm{S}\right)$, 3.67 (m, 8H, O-CH $\left.2-\mathrm{CH}_{2}-\mathrm{S}, \mathrm{O}-\mathrm{CH}_{2}-\mathrm{CH}_{2}-\mathrm{O}\right), 2.93$ (t, 4H, J=5Hz), 2.77 (t, 4H, J=5Hz), $2.54(\mathrm{~S}, 6 \mathrm{H}), 1.48(\mathrm{~S}, 6 \mathrm{H}) .{ }^{13} \mathrm{C} \mathrm{NMR}\left(100 \mathrm{MZ}, \mathrm{CDCl}_{3}\right): \delta 13.5,13.7,28.3,30.2,50.9$ 69.7, 73.4, 111.0, 119.9, 121.1, 128.1, 128.1, 131.2, 142.0, 142.2, 146.4, 153.7. MALDI MS m/z $573.9\left(\mathrm{C}_{29} \mathrm{H}_{38} \mathrm{BF}_{2} \mathrm{~N}_{3} \mathrm{O}_{2} \mathrm{~S}_{2}\right.$ requires 573.25)

Elemental analysis calcd (\%) for $\mathrm{C}_{29} \mathrm{H}_{38} \mathrm{BF}_{2} \mathrm{~N}_{3} \mathrm{O}_{2} \mathrm{~S}_{2}$ (573.25): C, 60.73; H, 6.68; N, 7.33. Found: C, 61.14; H, 6.90; N, 7.00. 


\section{3-\{2'-[4"-(10-Phenyl-1,4-dioxa-7,13-dithia-10-azacyclopentadecane)]ethenyl $\}-4,4$}

'-difluoro-8-phenyl--1,3,5,7-tetramethyl-4-bora-3a,4a-diaza-s-indacene(4):

To

the

solution

of

4,4-Difluoro-1,3,5,7-tetramethyl-8-phenyl-4-bora-3a,4a,-diaza-s-indcene (5) (162mg, 0.5mmol) and 1,4-dioxa-7,13-dithia-10-(4-formylphenyl)-10-azacyclopentadecane 2 (205.7mg, $0.55 \mathrm{mmol})$ in $40 \mathrm{~mL}$ of toluene were added, glacial acetic acid (375 $\mu \mathrm{l})$, piperidine $(450 \mu \mathrm{l})$ and small amount of $\mathrm{Mg}\left(\mathrm{ClO}_{4}\right)_{2}$. The resulting mixture was refluxed, and the water formed during the reaction was removed azeotropically by heating overnight in a Dean-Stark apparatus. The solvent was removed under vacuum, and the residue was purified by silica gel column chromatography $\left(\mathrm{CH}_{2} \mathrm{Cl}_{2}\right.$ to $\left.\mathrm{CH}_{2} \mathrm{Cl}_{2} / \mathrm{MeOH}=100: 2\right)$. The blue fraction was collected to afford a purple solid. (94mg, 31\%). ${ }^{1} \mathrm{H}$ NMR (400MZ, $\left.\mathrm{CDCl}_{3}\right): \delta 7.50(\mathrm{~m}, 6 \mathrm{H}), 7.30(\mathrm{~d}, 2 \mathrm{H}), 7.20(\mathrm{~d}, 1 \mathrm{H}), 6.63$ (d, 2H), $6.58(\mathrm{~s}, 1 \mathrm{H}), 5.96(\mathrm{~s}, 1 \mathrm{H}), 3.82(\mathrm{~m}, 4 \mathrm{H}), 3.68(\mathrm{~m}, 8 \mathrm{H}), 2.92(\mathrm{~m}, 4 \mathrm{H}), 2.77(\mathrm{~m}, 4 \mathrm{H})$ $2.58(\mathrm{~s}, 3 \mathrm{H}), 1.41(\mathrm{~s}, 3 \mathrm{H}), 1.37(\mathrm{~s}, 3 \mathrm{H}) ;{ }^{13} \mathrm{C} \mathrm{NMR}\left(100 \mathrm{MZ}, \mathrm{CDCl}_{3}\right): \delta$ 154.78, 153.12 $147.86,142.93,140.97,139.03,137.51,135.5,133.17,131.33,129.70,129.11,128.89$, $128.51,124.91,120.57,117.8,114.66,111.89,77.48,77.35,70.84,70.55,52.06,40.41$ $31.42, \quad 31.23,29.68,29.59,29.38, \quad 14.8, \quad 14.42$. MALDI $\quad$ MS $\mathrm{m} / \mathrm{z} 660.8$ $\left(\mathrm{C}_{29} \mathrm{H}_{38} \mathrm{BF}_{2} \mathrm{~N}_{3} \mathrm{O}_{2} \mathrm{~S}_{2}\right.$ requires 661.28).

3-\{2'-[4”-(10-Phenyl-1,4-dioxa-7,13-dithia-10-azacyclopentadecane)]ethenyl\}-4,4 '-difluoro-8-[1,4-dioxa-7,13-dithia-10-(4-formyphenyl)-10-azacyclopentadecanyl] -1,3,5,7-tetramethyl-4-bora-3a,4a-diaza-s-indacene (DMS1): To the solution of 
4,4-difluoro-8-[1,4-Dioxa-7,13-dithia-10-(4-Formyphenyl)-10-azacyclopentadecanyl] -1,3,5,7-tetramethyl-4-bora-3a,4a-diaza-s-indacene $3(163 \mathrm{mg}, \quad 0.28 \mathrm{mmol})$ and 1,4-dioxa-7,13-dithia-10-(4-formylphenyl)-10-azacyclopentadecane $2 \quad(160.5 \mathrm{mg}$, $0.31 \mathrm{mmol})$ in $20 \mathrm{~mL}$ of toluene were added, glacial acetic acid $(213 \mu \mathrm{l})$, piperidine (255.6 $\mu \mathrm{l})$ and small amount of $\mathrm{Mg}\left(\mathrm{ClO}_{4}\right)_{2}$. The resulting mixture was refluxed, and the water formed during the reaction was removed azeotropically by heating overnight in a Dean-Stark apparatus. The solvent was removed under vacuum, and the residue was purified by silica gel column chromatography $\left(\mathrm{CH}_{2} \mathrm{Cl}_{2}\right.$ to $\left.\mathrm{CH}_{2} \mathrm{Cl}_{2} / \mathrm{MeOH}=100: 1\right)$. The blue fraction was collected to afford a purple solid. (88mg, 34\%). ${ }^{1} \mathrm{H}$ NMR (400MZ, $\left.\mathrm{CDCl}_{3}\right): \quad 77.47(\mathrm{~m}, 3 \mathrm{H}), 7.16(\mathrm{~d}, 2 \mathrm{H}), 7.06(\mathrm{~d}, 2 \mathrm{H}), 6.71(\mathrm{~d}, 2 \mathrm{H}), 6.62(\mathrm{~d}, 2 \mathrm{H})$, $6.58(\mathrm{~s}, 1 \mathrm{H}), 5.95(\mathrm{~s}, 1 \mathrm{H}), 3.82(\mathrm{~m}, 8 \mathrm{H}), 3.67(\mathrm{~m}, 16 \mathrm{H}), 2.94(\mathrm{~m}, 8 \mathrm{H}), 2.77(\mathrm{~m}, 8 \mathrm{H})$ $2.57(\mathrm{~s}, 3 \mathrm{H}), 1.52(\mathrm{~s}, 3 \mathrm{H}), 1.48(\mathrm{~s}, 3 \mathrm{H}) ;{ }^{13} \mathrm{C} \mathrm{NMR}\left(100 \mathrm{MZ}, \mathrm{CDCl}_{3}\right): \delta$ 154.07, 152.62, $147.63,147.18,142.89,141.07,140.27,136.78,133.74,132.00,129.52,129.45$ $124.98,122.60,120.22,117.34,114.83,111.95,111.80,74.41,74.25,70.76,70.74$ 51.95, 51.89, 31.34, 31.23, 29.68, 29.59, 29.38, 15.02, 14.62. MALDI MS m/z 910.2 $\left(\mathrm{C}_{29} \mathrm{H}_{38} \mathrm{BF}_{2} \mathrm{~N}_{3} \mathrm{O}_{2} \mathrm{~S}_{2}\right.$ requires 911.37). Elemental analysis calcd (\%) for $\mathrm{C}_{46} \mathrm{H}_{61} \mathrm{BF}_{2} \mathrm{~N}_{4} \mathrm{O}_{4} \mathrm{~S}_{4}$ (911.37): C, 60.64; H, 6.75; N, 6.15. Found: C, 60.51; H, 6.95; N, 6.04 .

\section{§7. The characterization data of all compound.}

\footnotetext{
${ }^{1} \mathrm{H}$ NMR of 1,4-Dioxa-7,13-dithia-10-(4-formylphenyl)-10-azacyclopentadecane(2):
} 


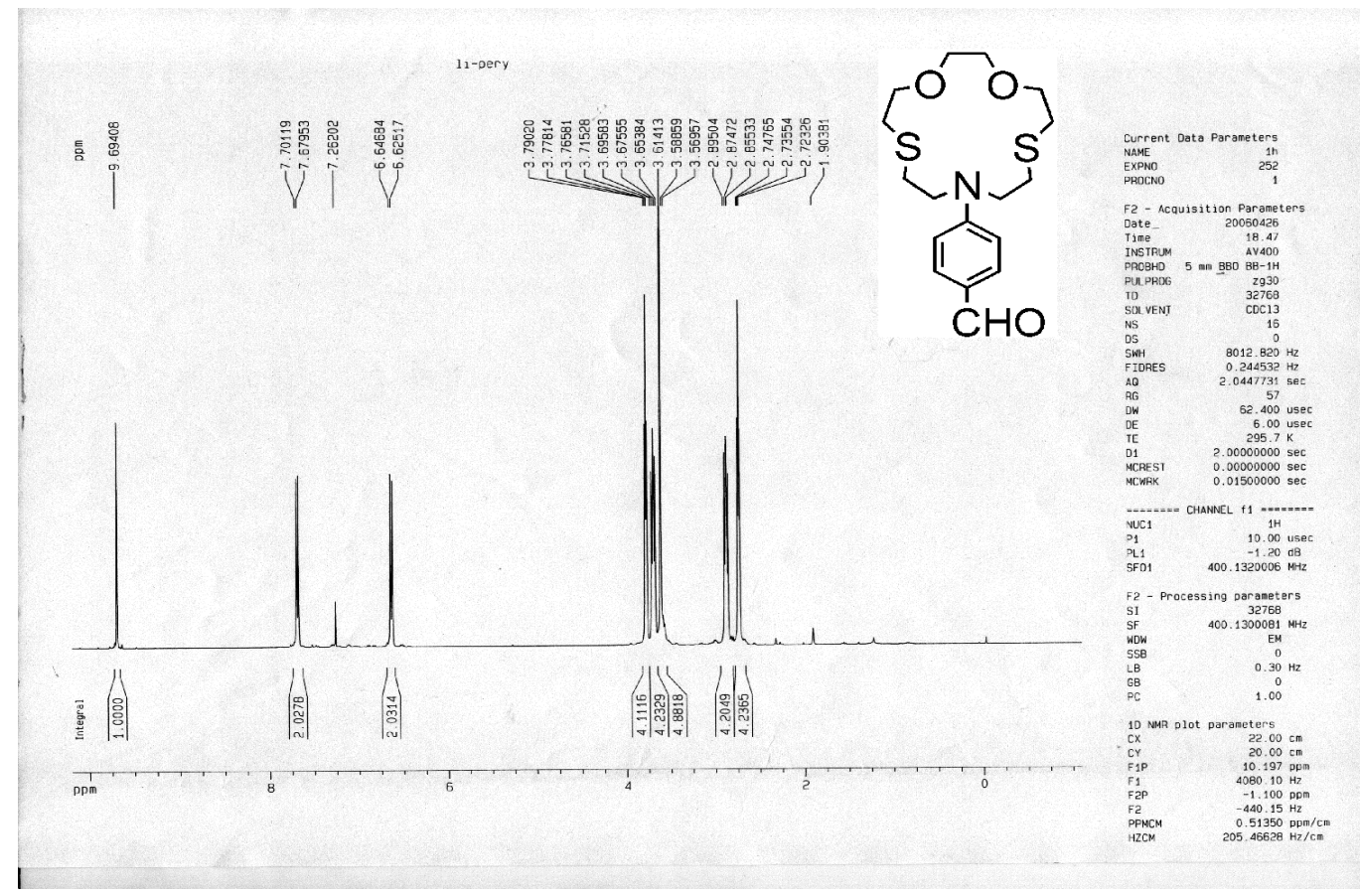

${ }^{13}$ C NMR of 1,4-Dioxa-7,13-dithia-10-(4-formylphenyl)-10-azacyclopentadecane(2):

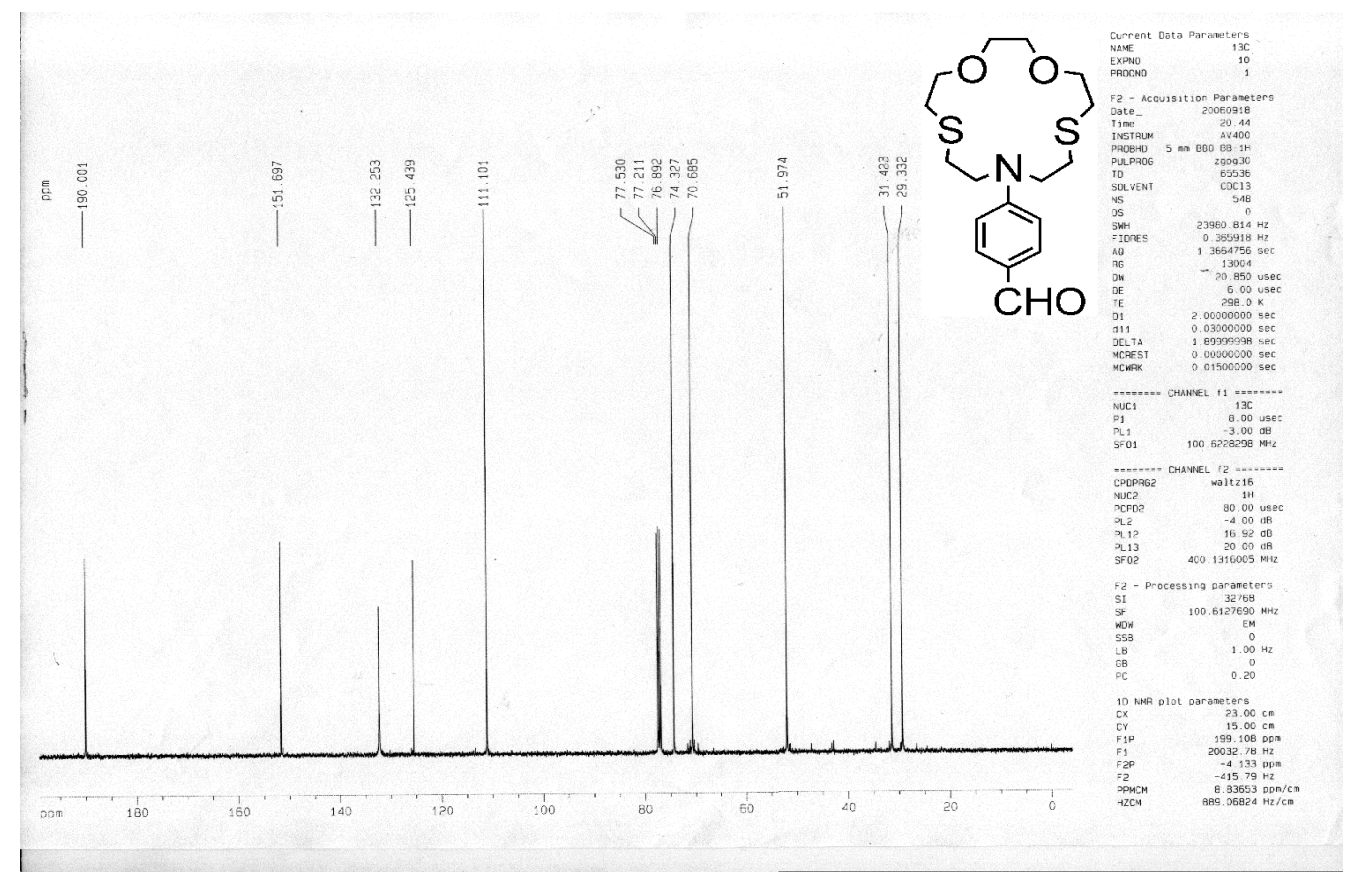

${ }^{1}$ H NMR of 4,4-Difluoro-8-[1,4-dioxa-7,13-dithia-10-(4-formyphenyl)-10azacyclopentadecanyl]-1,3,5,7-tetramethyl-4-bora-3a,4a-diaza-s-indacene(3) 


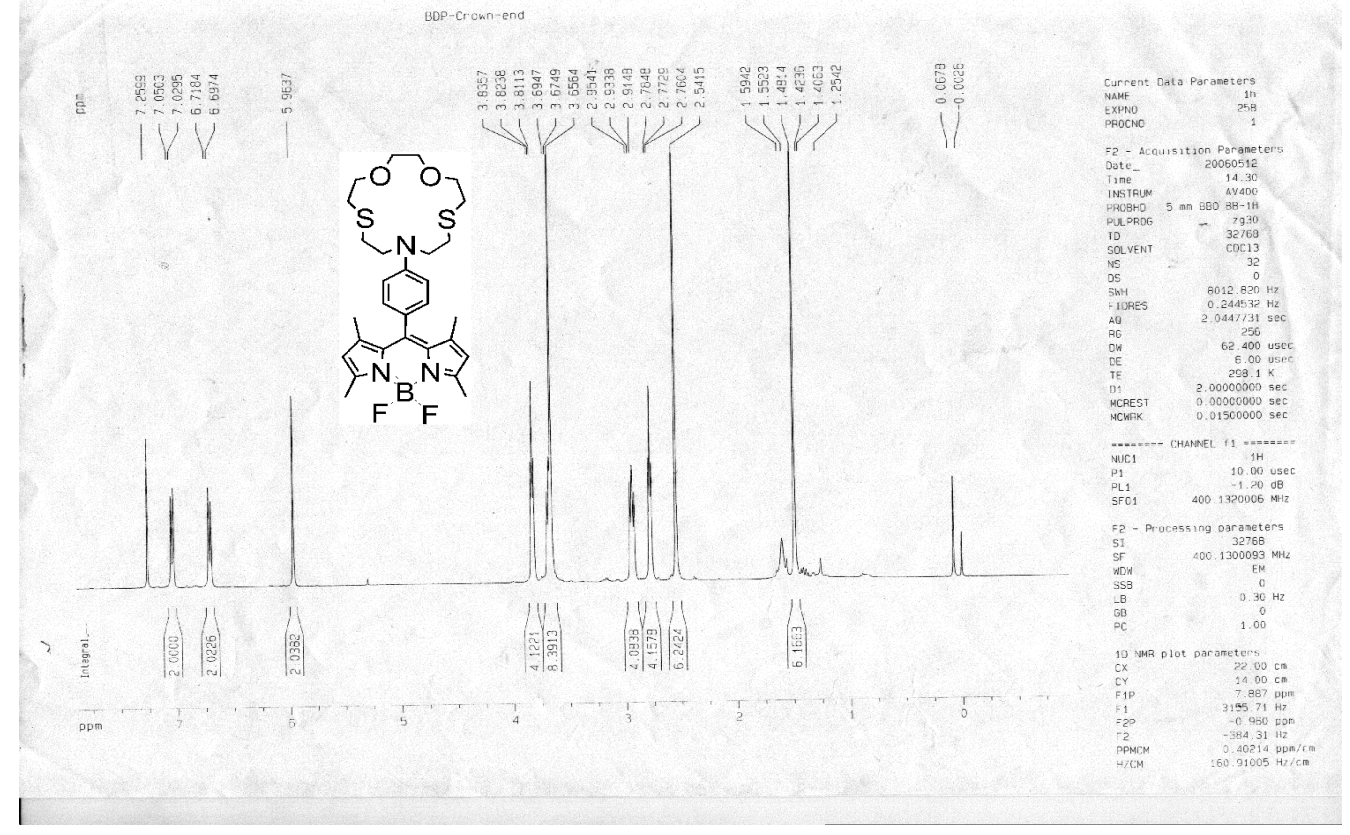

${ }^{13} \mathrm{C}$ NMR of 4,4-Difluoro-8-[1,4-dioxa-7,13-dithia-10-(4-formyphenyl)-10azacyclopentadecanyl]-1,3,5,7-tetramethyl-4-bora-3a,4a-diaza-s-indacene(3)

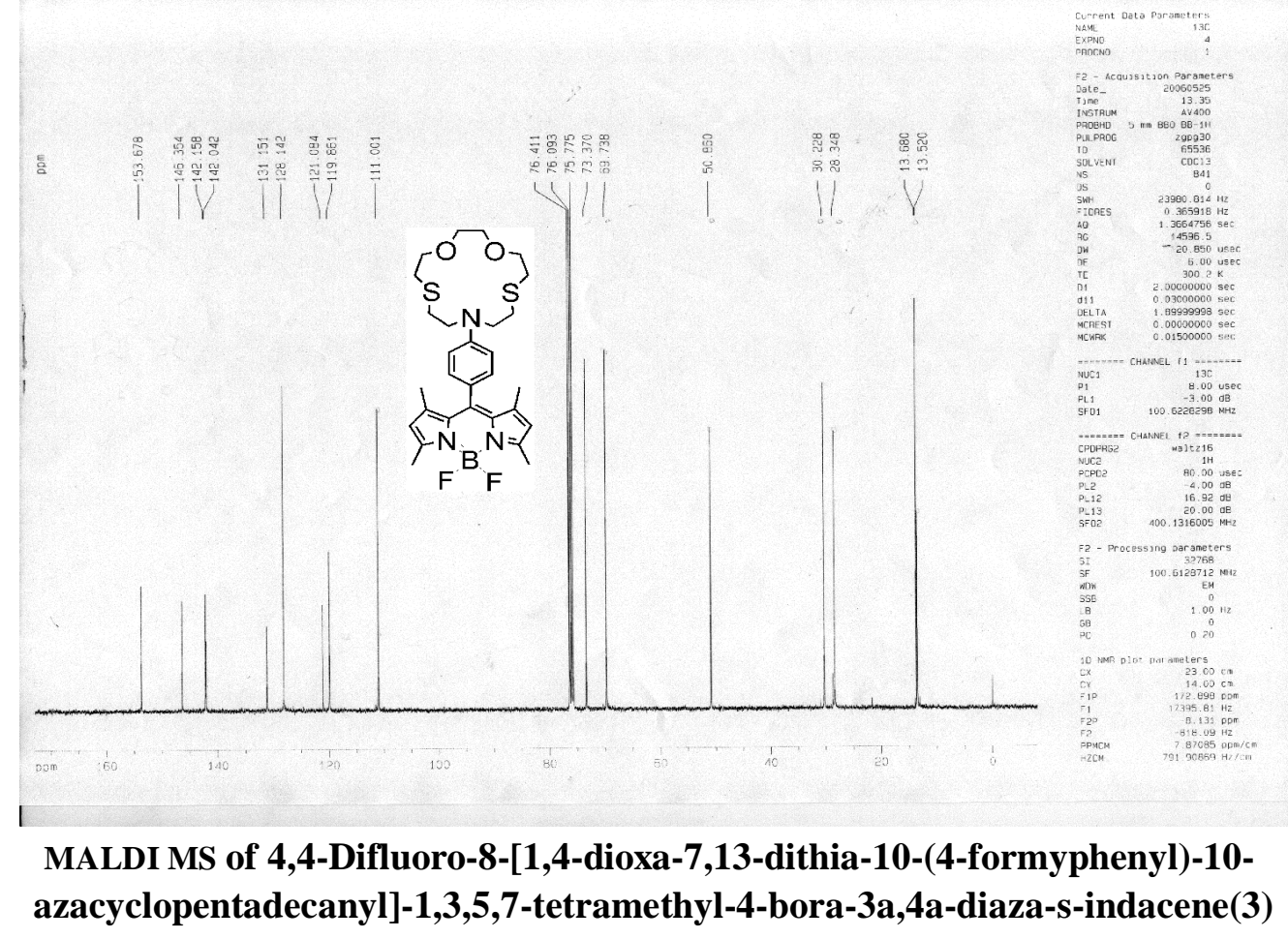




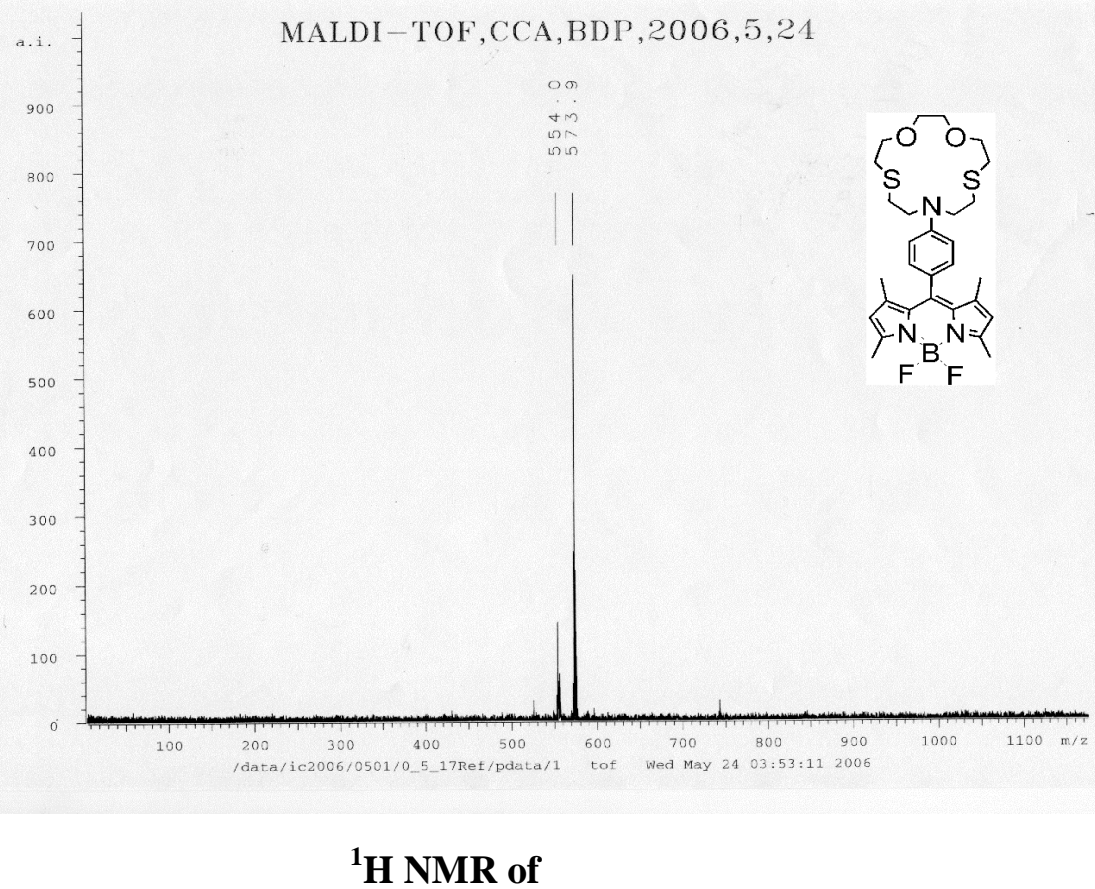

3-\{2'-[4”-(10-Phenyl-1,4-dioxa-7,13-dithia-10-azacyclopentadecane)]ethenyl $\}-4,4$

'-difluoro-8-phenyl--1,3,5,7-tetramethyl-4-bora-3a,4a-diaza-s-indacene(4):

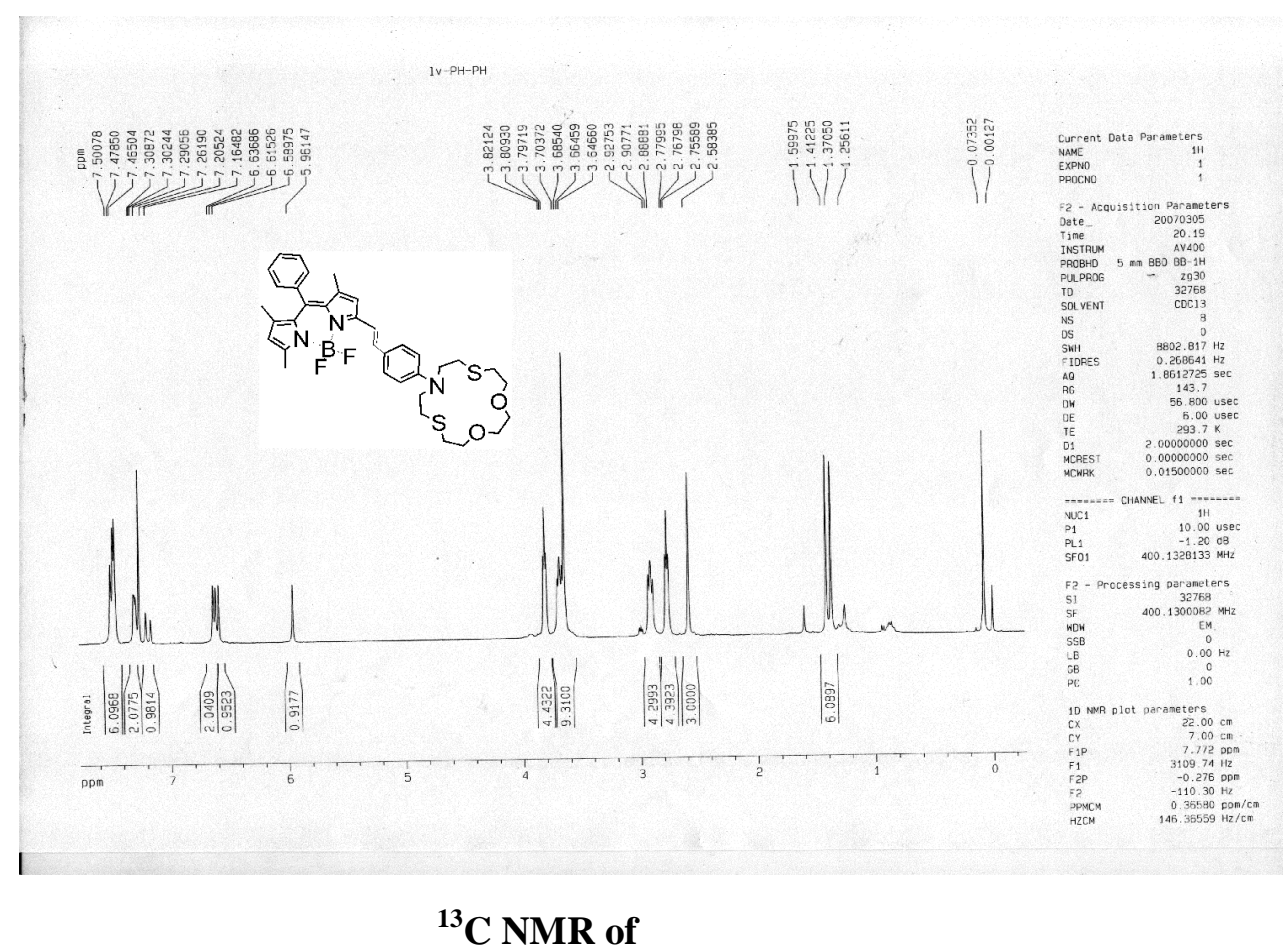

3-\{2'-[4"-(10-Phenyl-1,4-dioxa-7,13-dithia-10-azacyclopentadecane)]ethenyl $\}-4,4$ 
'-difluoro-8-phenyl--1,3,5,7-tetramethyl-4-bora-3a,4a-diaza-s-indacene(4):

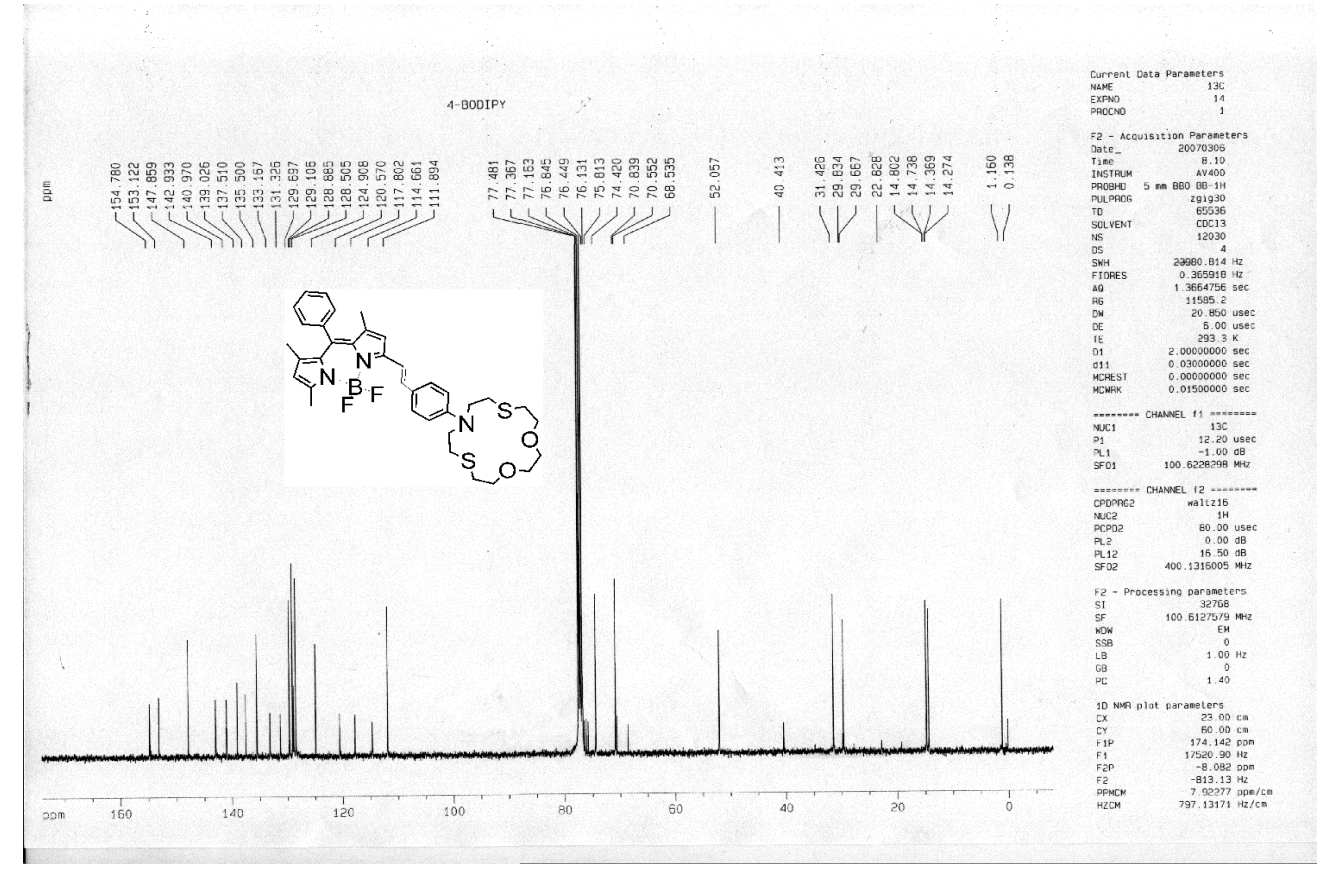

MALDI MS of

3-\{2'-[4”-(10-Phenyl-1,4-dioxa-7,13-dithia-10-azacyclopentadecane)]ethenyl\}-4,4

'-difluoro-8-phenyl--1,3,5,7-tetramethyl-4-bora-3a,4a-diaza-s-indacene(4):

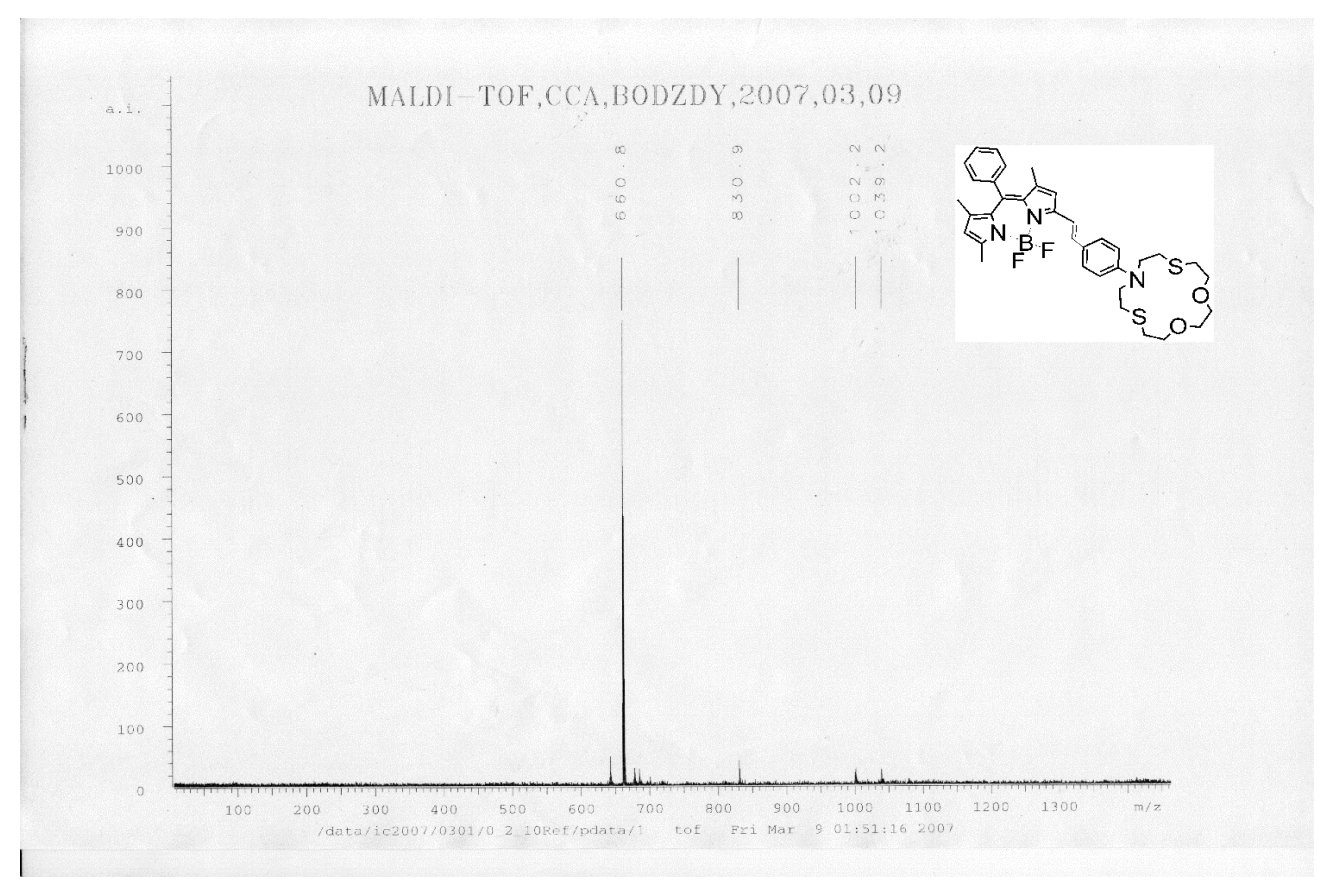

3-\{2'-[4"'-(10-Phenyl-1,4-dioxa-7,13-dithia-10-azacyclopentadecane)]ethenyl\}-4,4 
'-difluoro-8-[1,4-dioxa-7,13-dithia-10-(4-formyphenyl)-10-azacyclopentadecanyl]

-1,3,5,7-tetramethyl-4-bora-3a,4a-diaza-s-indacene (DMS1)- ${ }^{1} \mathrm{H}$ NMR :

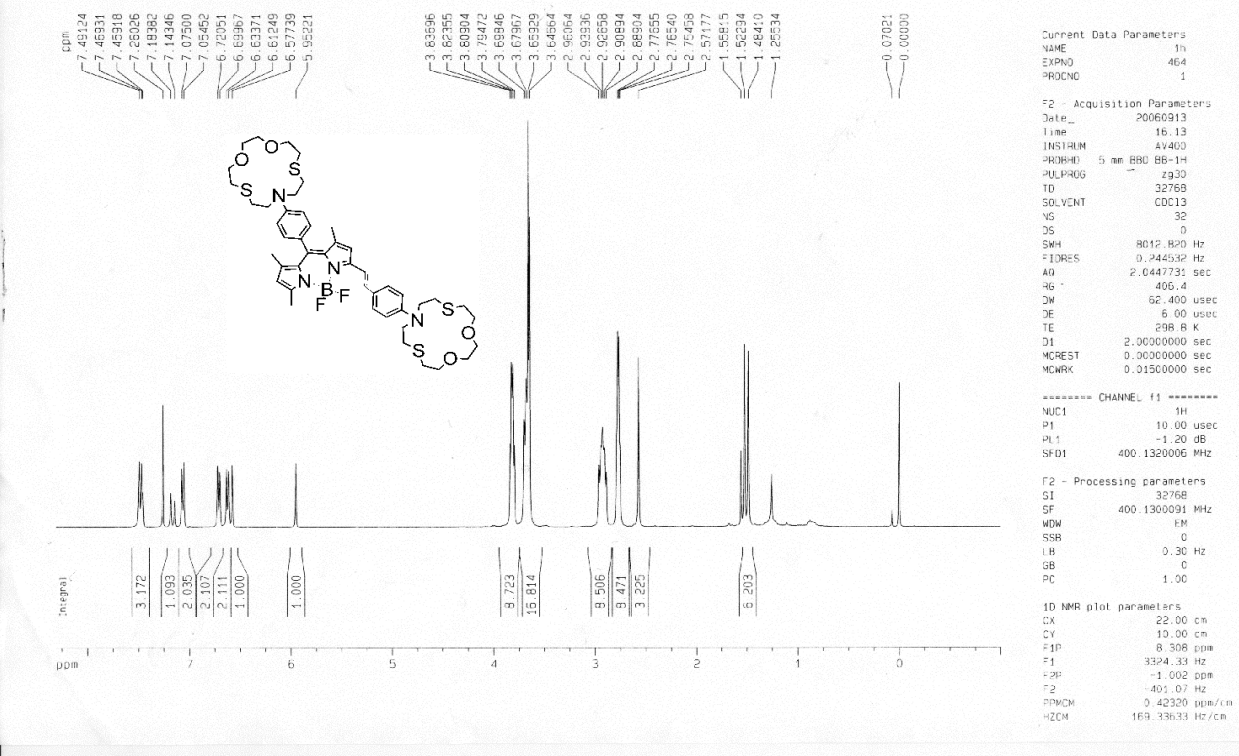

3-\{2'-[4”'-(10-Phenyl-1,4-dioxa-7,13-dithia-10-azacyclopentadecane)]ethenyl $\}-4,4$

'-difluoro-8-[1,4-dioxa-7,13-dithia-10-(4-formyphenyl)-10-azacyclopentadecanyl]

-1,3,5,7-tetramethyl-4-bora-3a,4a-diaza-s-indacene (DMS1)- ${ }^{13} \mathrm{C}$ NMR :
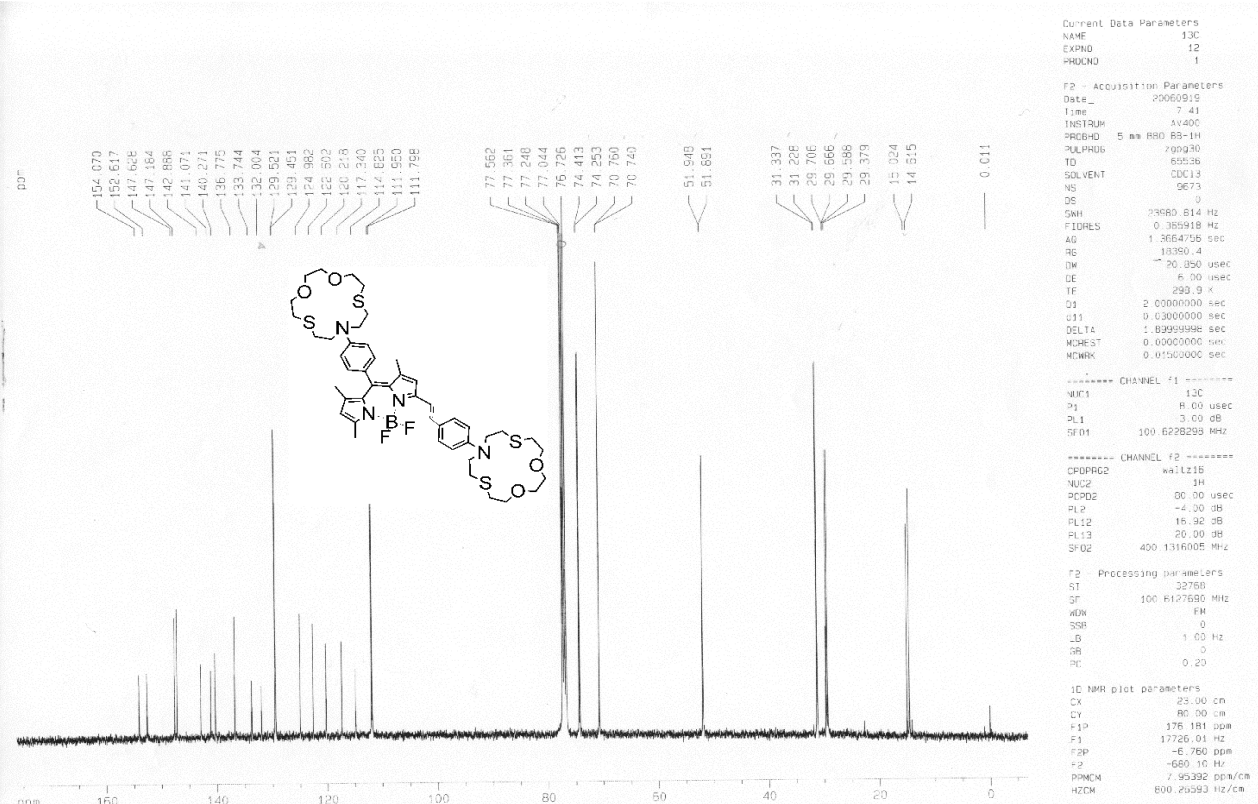
3-\{2'-[4"'-(10-Phenyl-1,4-dioxa-7,13-dithia-10-azacyclopentadecane)]ethenyl $\}-4,4$

'-difluoro-8-[1,4-dioxa-7,13-dithia-10-(4-formyphenyl)-10-azacyclopentadecanyl]

-1,3,5,7-tetramethyl-4-bora-3a,4a-diaza-s-indacene (DMS1)- MALDI MS

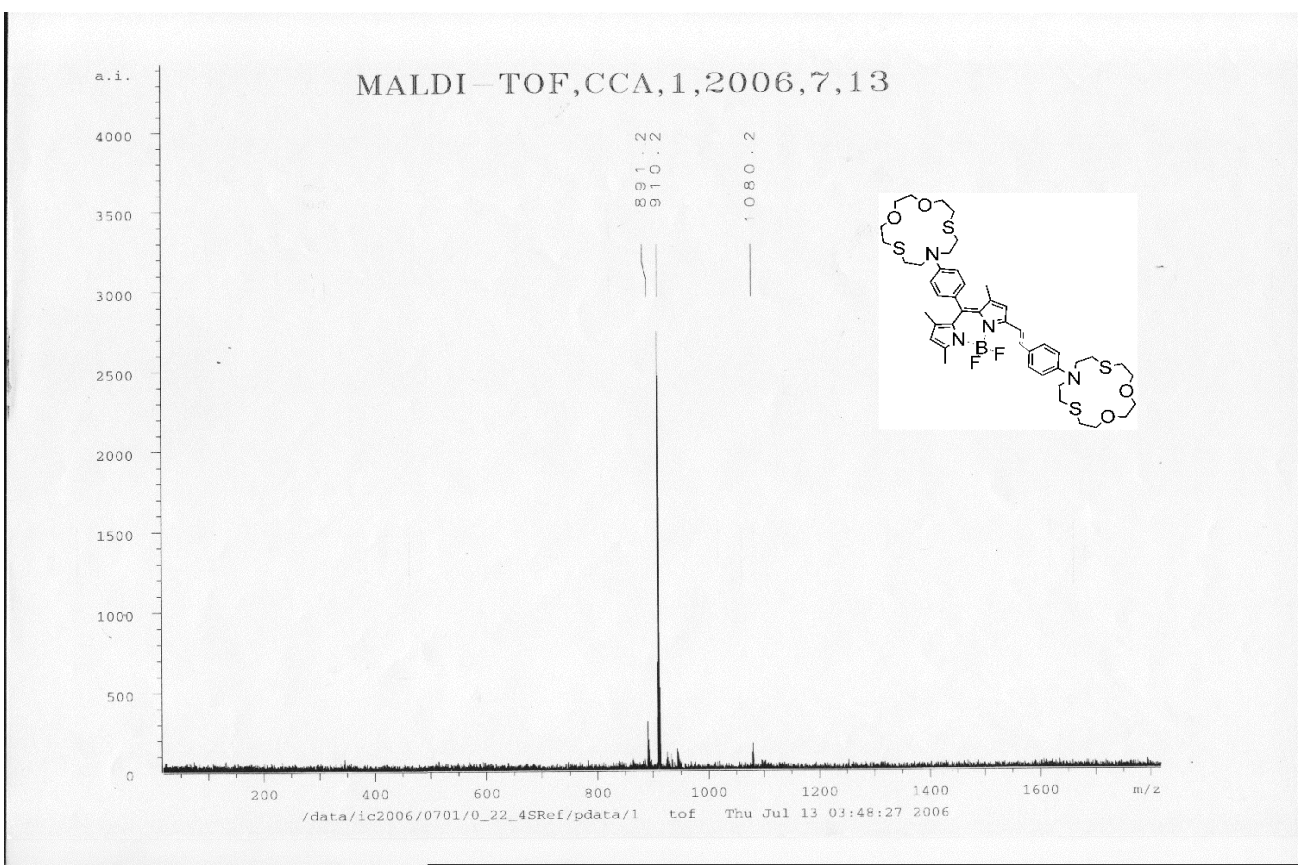

